\title{
Clinicoetiological Characterization of Infectious Vaginitis amongst Women of Reproductive Age Group from Navi Mumbai, India
}

\author{
Anuradha Narayankhedkar, ${ }^{1}$ Anahita Hodiwala, ${ }^{2}$ and Arati Mane ${ }^{3}$ \\ ${ }^{1}$ Shahbazker's Diagnostics Pvt. Ltd., Mumbai, Maharashtra 400005, India \\ ${ }^{2}$ Department of Microbiology, MGM Medical College, Navi Mumbai, Maharashtra 410209, India \\ ${ }^{3}$ Department of Microbiology \& Clinical Pathology, National AIDS Research Institute, Pune, Maharashtra 411026, India
}

Correspondence should be addressed to Arati Mane; amane@nariindia.org

Received 28 May 2015; Revised 10 August 2015; Accepted 11 August 2015

Academic Editor: Kingsley C. Anukam

Copyright (C) 2015 Anuradha Narayankhedkar et al. This is an open access article distributed under the Creative Commons Attribution License, which permits unrestricted use, distribution, and reproduction in any medium, provided the original work is properly cited.

\begin{abstract}
Vaginitis is one of the commonest reproductive tract infections in sexually active women. In the present study clinicoetiological characterization of infectious vaginitis amongst 380 women of reproductive age group (18-45 years) was done. Bacterial vaginosis (BV) was detected by Nugent's scoring, Candida infection by culture, and trichomoniasis (TV) by wet mount. One hundred and ten $(28.9 \%)$ women presented with symptoms of vaginitis. The presenting symptoms were vaginal discharge 106 (96.4\%), vulval itching/irritation $19(17.3 \%)$, malodor $5(4.5 \%)$, pain in abdomen $3(2.7 \%)$, and dysuria $1(0.9 \%)$. The commonest etiology detected was Candida in 33 (30\%) cases, of which 18 (54.5\%) were C. albicans and 15 (45.5\%) non-albicans Candida (NAC) infections. The NAC isolates were C. glabrata $(n=10)$, C. tropicalis $(n=3)$, and C. krusei $(n=2)$. BV and TV were observed in $19(17.3 \%)$ and 2 $(1.8 \%)$ cases, respectively. A statistically significant association between Candida infection and presence of curdy-white discharge ( $p=0.001)$ and vulval itching/irritation $(p=0.007)$ was noted. To conclude, we observed the etiological predominance of Candida infection, with considerable prevalence of NAC, indicating the need for microbiological investigation up to species level in cases of Candida infections, to ensure appropriate management.
\end{abstract}

\section{Introduction}

Reproductive tract infections (RTI) including sexually transmitted infections (STI) present a huge disease burden and adversely impact the reproductive health. Their consequences are far more devastating and widespread among women as compared to men $[1,2]$. Vaginitis is one of the commonest RTI and is characterized by vaginal discharge, vulvar itching/irritation, and malodor. It encompasses three main etiologies, namely, bacterial vaginosis (BV), vaginal candidiasis (VVC), and trichomoniasis (TV), which generally account for $90 \%$ of all etiologies.

$\mathrm{BV}$ is the most common cause of vaginal discharge among women in reproductive age. It is associated with an increased vaginal $\mathrm{pH}$ and replacement of vaginal Lactobacilli with Gardnerella vaginalis and anaerobic Gram-negative rods [3].
$\mathrm{BV}$ is of special public health concern because of the high burden of reproductive and pregnancy related morbidity [4]. Likewise high coinfection rates with other STI raise the possibility that BV increases susceptibility to STI $[4,5]$. VVC affects up to $75 \%$ of reproductive age women at least once during lifetime. Though majority of the infections are caused by Candida albicans the incidence of non-albicans Candida (NAC) infection is being increasingly reported nowadays probably due to low dosage azole maintenance regimens and the use of over-the-counter antimycotics [6]. Trichomonas vaginalis infection is the most common curable STI worldwide. Trichomoniasis is associated with infertility, enhanced predisposition to neoplastic transformation in cervical tissues, and an increased risk of transmission of other STI, including human immunodeficiency virus (HIV), by as much as twofold $[7,8]$. 
The symptoms of vaginitis are nonspecific and diagnosis without laboratory confirmation can lead to inappropriate medication [6]. Furthermore the etiological profile varies from country to country and from one region to another within the same country. The present study was undertaken for the clinicoetiological characterization of infectious vaginitis amongst women of reproductive age group attending the outpatient clinic of Obstetrics and Gynaecology Department from Navi Mumbai, India.

\section{Materials and Methods}

The cross-sectional observational study was conducted in the Department of Microbiology in association with the Department of Obstetrics and Gynaecology at MGM Medical College and Hospital, which is a referral and teaching hospital located in Kamothe, Navi Mumbai, India. A part of the study was carried out at National AIDS Research Institute, Pune. The study was approved by the institutional Ethics Committee of the MGM Medical College and Hospital.

A total of 380 women attending the clinic from July to December 2014 were screened for symptoms of vaginitis. The inclusion criteria were women with age between 18 and 45 years and presenting with symptoms of vaginal discharge, vulval itching/irritation, and/or vaginal malodor. Women who were pregnant, who were menstruating, who had received antibiotics in the past 4 weeks, and who were not consenting to participate were excluded.

2.1. Specimen Collection and Processing. Informed written consent was taken from patient before enrolment in the study, followed by detailed physical examination of the patient. Per speculum examination was performed and the vaginal mucosa was inspected for presence of erythema, lesions, and discharge. Vaginal material was collected from the lateral vaginal wall with cotton-swab. Three swabs per patient were collected.

The first swab was used to determine the vaginal $\mathrm{pH}$ by touching a $\mathrm{pH}$ strip and comparing the change against a reference reader; it was then smeared on to a glass slide for Gram staining and finally 2 drops of $10 \%$ potassium hydroxide were added to it to determine amine/fishy odour (whiff test). The Gram stained slides were evaluated using Nugent's scoring system for detection of BV [9]. A Nugent score of 0-3 was interpreted as negative for BV and a score of 4-6 as intermediate while a score of 7-10 was interpreted as consistent with $\mathrm{BV}$.

The second swab was placed in screw-cap plastic tubes containing $0.5 \mathrm{~mL}$ of $0.9 \%$ saline to carry out wet mount microscopy for detection of TV. Swab was vigorously rotated in the saline and pressed against the side of the tube to express as much fluid as possible. One drop of the expressed fluid was placed on glass slide with a cover slip and examined at magnification of 200x within 15 minutes of collection of the sample. The positive result was defined as the presence of one or more Trichomonads with characteristic morphology and jerky motility [10].

The third swab was used for Candida culture on Sabouraud's dextrose agar followed by incubation at $37^{\circ} \mathrm{C}$
TABle 1: Attributes of vaginal discharge.

\begin{tabular}{|c|c|c|}
\hline Attribute & $\begin{array}{l}\text { Number } \\
N=106\end{array}$ & Percentage \\
\hline \multicolumn{3}{|c|}{ Color } \\
\hline White & 87 & 82.1 \\
\hline White curdy & 15 & 14.2 \\
\hline Greenish & 1 & 0.9 \\
\hline Creamish & 3 & 2.8 \\
\hline \multicolumn{3}{|c|}{ Quantity } \\
\hline Scanty & 26 & 24.5 \\
\hline $\begin{array}{l}\text { Moderate to } \\
\text { copious }\end{array}$ & 80 & 75.5 \\
\hline \multicolumn{3}{|c|}{ Consistency } \\
\hline Thin & 43 & 40.6 \\
\hline Thick & 63 & 59.4 \\
\hline \multicolumn{3}{|c|}{ Duration } \\
\hline$\geq 15$ days & 30 & 28.3 \\
\hline$<15$ days & 76 & 71.7 \\
\hline \multicolumn{3}{|c|}{$\mathrm{pH}$} \\
\hline 4 & 54 & 50.9 \\
\hline 5 & 37 & 34.9 \\
\hline$>5$ & 15 & 14.2 \\
\hline \multicolumn{3}{|c|}{ Malodor } \\
\hline Present & 5 & 4.7 \\
\hline Absent & 101 & 95.3 \\
\hline
\end{tabular}

for $48 \mathrm{~h}$. Candida isolates were identified by the standard mycological techniques like cultural characteristics, Gram stain, germ tube formation, and the biochemical profile on API 20 C AUX (BioMerieux, France) [11]. All cases with Candida as the etiological agent also had a clinical diagnosis of VVC.

2.2. Statistical Analysis. The GraphPad statistical software (GraphPad Software Inc., USA) was used for statistical analysis. Descriptive analysis was performed for all variables and data presented as percentages. The Chi-square or Fisher's exact test as applicable was applied for analysis of categorical variables. A $p$ value of $<0.05$ was considered to be statistically significant.

\section{Results}

Of the 380 women screened, 110 (28.9\%) had symptoms of vaginitis. The prevalence of infectious etiologies, namely, bacterial vaginosis, candidiasis, and trichomoniasis, was determined in these women. The median age of the women was 28 years (interquartile range, 24-32); all of them were married and cohabiting with their husbands, while 13 (11.8\%) were nulliparous, 48 (43.6\%) primiparous, and the rest multiparous.

The presenting symptoms were vaginal discharge 106 (96.4\%), vulval itching/irritation 19 (17.3\%), malodor 5 $(4.5 \%)$, pain in abdomen $3(2.7 \%)$, and dysuria $1(0.9 \%)$.

The attributes of vaginal discharge are presented in Table 1 . 
TABLE 2: Age-wise distribution of vaginitis.

\begin{tabular}{|c|c|c|c|}
\hline Age group & $\begin{array}{c}\text { Infectious vaginitis } \\
N(\%)\end{array}$ & $\begin{array}{c}\text { Bacterial vaginosis } \\
N(\%)\end{array}$ & $\begin{array}{c}\text { Candidiasis } \\
N(\%)\end{array}$ \\
\hline 18 to $\leq 24$ years & $24(44.4)$ & $10(52.6)$ & $16(48.5)$ \\
\hline 25 to $\leq 34$ years & $21(38.9)$ & $6(31.6)$ & $13(39.4)$ \\
\hline 35 to 45 years & $9(16.7)$ & $3(15.8)$ & $4(12.1)$ \\
\hline
\end{tabular}

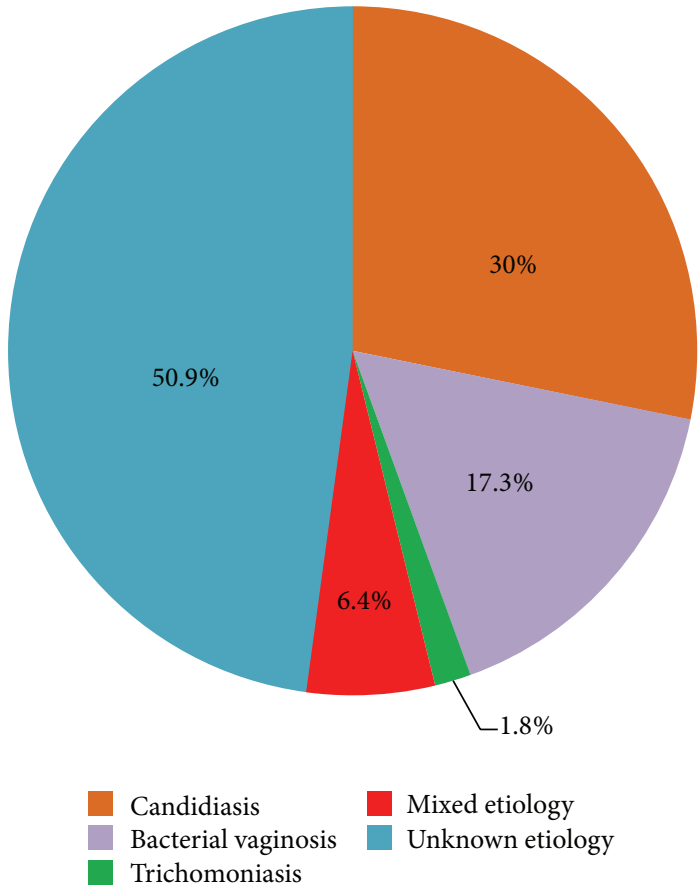

FIGURE 1: Distribution of etiologies of infectious vaginitis.

In the 110 women presenting with vaginitis, 54 (49.1\%) infectious etiologies were identified. The etiological agent was identified in 47 (42.7\%) women, of which 7 (14.9\%) had mixed etiologies. Figure 1 shows the etiological distribution in infectious vaginitis.

The commonest etiology was candidiasis detected in $33 / 110(30 \%)$ cases. C. albicans was isolated in 18/33 (54.5\%) cases, while $15 / 33(45.5 \%)$ cases had NAC isolates. The NAC isolated were C. glabrata $(n=10), C$. tropicalis $(n=3)$, and C. $k r u s e i(n=2)$.

BV (Nugent's score 7-10) was observed in 19/110 (17.3\%) cases. TV was detected in 2/110 (1.8\%) cases. Mixed etiologies detected were BV + VVC in six cases and BV + TV in one case.

We observed a trend of decrease in the prevalence of infectious vaginitis with age as presented in Table 2; however the difference was not statistically significant between the different age groups $(p=0.187)$.

The association between clinical symptoms and microbiological diagnosis is presented in Table 3. A statistically significant association between candidal infection and the presence of curdy-white discharge (0.001) and vulval itching/irritation $(p=0.007)$ was noted.
TABLE 3: The association between clinical symptoms and microbiological diagnosis.

\begin{tabular}{|c|c|c|c|c|}
\hline & \multicolumn{2}{|c|}{$\begin{array}{c}\text { Candidiasis } \\
n=33\end{array}$} & \multicolumn{2}{|c|}{$\begin{array}{c}\text { Bacterial vaginosis } \\
n n=19\end{array}$} \\
\hline & $\begin{array}{l}\text { Present } \\
N(\%)\end{array}$ & $p$ & $\begin{array}{l}\text { Present } \\
N(\%)\end{array}$ & $p$ \\
\hline $\begin{array}{l}\text { Vaginal discharge } \\
n=106\end{array}$ & $32(30.2)$ & 1.00 & $17(16.03)$ & 0.137 \\
\hline $\begin{array}{l}\text { Curdy-white discharge } \\
n=15\end{array}$ & $13(86.7)$ & 0.001 & $1(6.7)$ & 0.297 \\
\hline $\begin{array}{l}\text { Vulval itching/irritation } \\
n=19\end{array}$ & $12(63.2)$ & 0.007 & $4(21.1)$ & 0.519 \\
\hline $\begin{array}{l}\text { Pain in abdomen } \\
n=3\end{array}$ & - & 0.552 & $2(66.7)$ & 0.076 \\
\hline $\begin{array}{l}\text { Malodor } \\
n=5\end{array}$ & $1(25)$ & 1.000 & $2(40)$ & 0.205 \\
\hline $\begin{array}{l}\text { Dysuria } \\
n=1\end{array}$ & - & 1.000 & $1(100)$ & 0.172 \\
\hline
\end{tabular}

The group of women with candidiasis and bacterial vaginosis were compared with the respective group of women without infection. Trichomoniasis was not included as there were only 2 cases.

\section{Discussion}

Vaginitis is the commonest RTI in sexually active women and is associated with a significant risk of morbidity. The management of vaginitis remains largely empirical, though establishing correct diagnosis is the most important factor for successful treatment [12]. Variable prevalence rates of infectious vaginitis, attributable to the varied etiologies studied, the detection techniques applied, patient groups involved, and the geographical locales have been reported by studies conducted globally as well as in India [13-18]. In the present study majority of symptomatic women had unidentified etiology. This finding requires due consideration and indicates the need for looking into other etiological agents including but not limited to gonorrhea, chlamydiasis, viruses that may lead to vaginitis.

VVC was the commonest infectious etiology identified in the present study and its prevalence was consistent with earlier reports [13, 19-24]. The distribution of Candida spp. identified in women with VVC varies widely depending on the locations as well as the populations studied [25]. Recently a number of studies have shown an increasing trend of NAC infection [20, 21, 26]. Though C. albicans remained the predominant species isolated in the present study, NAC were isolated in considerable proportions. Furthermore in 
accordance with previous literature C. glabrata was the commonest NAC isolated [21, 27]. With higher resistance levels of most NAC species to the commonly prescribed azolebased treatments, the consequences for women affected by these strains might be incapacitating. Hence microbiological investigation up to species level should be made mandatory for Candida infections to ensure appropriate management.

The prevalence of bacterial vaginosis in present study is $17.3 \%$. Various studies show prevalence of $\mathrm{BV}$ ranges from $2.5 \%$ to $48 \%$ [14, 17, 28-33]. These variations may be because of differences in study population, economic status, educational background, and method used for detection of bacterial vaginosis [30]. The prevalence of $\mathrm{BV}$ in the present study is in accordance with other reports from India [4, 29]. It is noteworthy that the mixed microbial etiologies observed were all seen in association with BV. It may thus be speculated that women with BV tend to lose natural protection against genital tract infections leading to acquisition of coinfections like T. vaginalis and Candida. The mechanisms underlying these relationships are not well understood and warrant further investigation [4].

Relatively lower prevalence of trichomoniasis $(1.8 \%)$ was observed in our study, a finding consistent with researchers' earlier reports $[14,15,18,29,30,34]$. On the contrary, a number of studies have reported a higher prevalence of TV than ours [35-38]. These differences could be due to variation in personal hygiene practice, environment, and socioeconomic and cultural factors of the study participants [14]. Moreover, the detection of TV by conventional wet mount method in the present study might have reduced the actual prevalence.

To conclude, we present here the clinical and etiological characterization of infectious vaginitis amongst women of reproductive age group from Navi Mumbai, India. We observed the etiological predominance of Candida infection, with considerable prevalence of NAC, indicating the need for microbiological investigation up to species level in cases of Candida infections, to ensure appropriate management.

\section{Conflict of Interests}

The authors declare that there is no conflict of interests regarding the publication of this paper.

\section{References}

[1] P. S. Philip, A. I. Benjamin, and P. Sengupta, "Prevalence of symptoms suggestive of reproductive tract infections/sexually transmitted infections in women in an urban area of Ludhiana," Indian Journal of Sexually Transmitted Diseases, vol. 34, no. 2, pp. 83-88, 2013.

[2] Ministry of Health and Family Welfare Government of India, National Guidelines on Prevention, Management and Control of Reproductive Tract Infections Including Sexually Transmitted Infections, Ministry of Health and Family Welfare Government of India, 2007, http://naco.gov.in/upload/STI\%20RTI\%20services/ National_Guidelines_on_PMC_of_RTI_Including_STI\%201.pdf.

[3] T. L. Cherpes, L. A. Meyn, M. A. Krohn, J. G. Lurie, and S. L. Hillier, "Association between acquisition of herpes simplex virus type 2 in women and bacterial vaginosis," Clinical Infectious Diseases, vol. 37, no. 3, pp. 319-325, 2003.

[4] P. Madhivanan, K. Krupp, V. Chandrasekaran et al., "Prevalence and correlates of bacterial vaginosis among young women of reproductive age in Mysore, India," Indian Journal of Medical Microbiology, vol. 26, no. 2, pp. 132-137, 2008.

[5] P. Moodley, C. Connolly, and A. W. Sturm, "Interrelationships among human immunodeficiency virus type 1 infection, bacterial vaginosis, trichomoniasis, and the presence of yeasts," Journal of Infectious Diseases, vol. 185, no. 1, pp. 69-73, 2002.

[6] J. D. Sobel, "Vulvovaginal candidosis," The Lancet, vol. 369, no. 9577, pp. 1961-1971, 2007.

[7] O. Olowe, O. Makanjuola, R. Olowe, and D. Adekanle, "Prevalence of vulvovaginal candidiasis, trichomoniasis and bacterial vaginosis among pregnant women receiving antenatal care in Southwestern Nigeria," European Journal of Microbiology and Immunology, vol. 4, no. 4, pp. 193-197, 2014.

[8] J. S. Coleman, C. A. Gaydos, and F. Witter, "Trichomonas vaginalis vaginitis in obstetrics and gynecology practice: new concepts and controversies," Obstetrical and Gynecological Survey, vol. 68, no. 1, pp. 43-50, 2013.

[9] R. P. Nugent, M. A. Krohn, and S. L. Hillier, "Reliability of diagnosing bacterial vaginosis is improved by a standardized method of Gram stain interpretation," Journal of Clinical Microbiology, vol. 29, no. 2, pp. 297-301, 1991.

[10] J. S. McCann, "Comparison of direct microscopy and culture in the diagnosis of trichomoniasis," British Journal of Venereal Diseases, vol. 50, no. 6, pp. 450-452, 1974.

[11] A. Mane, S. Panchvalli, S. Bembalkar, and A. Risbud, "Species distribution \& antifungal susceptibility of oral Candida colonising or infecting HIV infected individuals," Indian Journal of Medical Research, vol. 131, no. 6, pp. 836-838, 2010.

[12] W. M. McCormack Jr., S. H. Zinner, and W. M. McCormack, "The incidence of genitourinary infections in a cohort of healthy women," Sexually Transmitted Diseases, vol. 21, no. 2, pp. 63-64, 1994.

[13] T. N. Gandhi, M. G. Patel, and M. R. Jain, "Prospective study of vaginal discharge and prevalence of Vulvovaginal candidiasis in a tertiary care hospital," International Journal of Current Research and Review, vol. 7, no. 1, pp. 34-38, 2015.

[14] M. Wondemagegn, M. Yimer, Y. Zenebe, and B. Abera, "Common causes of vaginal infections and antibiotic susceptibility of aerobic bacterial isolates in women of reproductive age attending at Felegehiwot referral Hospital, Ethiopia: a cross sectional study," BMC Women's Health, vol. 15, no. 42, pp. 1-9, 2015.

[15] M. A. Kadir, M. A. Sulyman, I. S. Dawood, and S. ShamsEldin, "Trichomonas vaginalis and associated microorganisms in women with vaginal discharge in Kerkuk-Iraq," Ankara Medical Journal, vol. 14, no. 3, pp. 91-99, 2014.

[16] G. Gupta, S. Nandwani, and A. Agarwal, "Prevalence of candidiasis, trichomoniasis and bacterial vaginosis among women of reproductive age group," Indian Journal of Public Health Research and Development, vol. 4, no. 2, pp. 94-98, 2013.

[17] A. Bahram, B. Hamid, and T. Zohre, "Prevalence of bacterial vaginosis and impact of genital hygiene practices in nonpregnant women in Zanjan, Iran," Oman Medical Journal, vol. 24, no. 4, pp. 288-293, 2009.

[18] R. Mathew, R. Sudhakshina, M. Kalyani, S. Jayakumar, B. Lal, and S. Banu, "Microbiological profile of vaginosis among women of reproductive age group attending a tertiary care 
hospital," Journal of Clinical and Diagnostic Research, vol. 5, no. 8, pp. 1548-1551, 2011.

[19] K. Puri, A. Madan, and K. Bajaj, "Incidence of various causes of vaginal discharge among sexually active females in age group 20-40 years," Indian Journal of Dermatology, Venereology and Leprology, vol. 69, no. 2, pp. 122-125, 2003.

[20] V. Kumari, T. Banerjee, P. Kumar, S. Pandey, and R. Tilak, "Emergence of non-albicans Candida among candidal vulvovaginitis cases and study of their potential virulence factors, from a tertiary care center, North India," Indian Journal of Pathology and Microbiology, vol. 56, no. 2, pp. 144-147, 2013.

[21] A. Ahmad and A. U. Khan, "Prevalence of Candida species and potential risk factors for vulvovaginal candidiasis in Aligarh, India," European Journal of Obstetrics Gynecology and Reproductive Biology, vol. 144, no. 1, pp. 68-71, 2009.

[22] A. Verma, A. Gupta, S. Goel, and A. Garg, "Clinicopathological correlation of infective vaginal discharges in non pregnant sexually active women of reproductive age group in a tertiary care centre of Western UP,' International Journal of Reproduction, Contraception, Obstetrics and Gynecology, vol. 2, no. 3, pp. 349354, 2013.

[23] N. Jindal, P. Gill, and A. Aggarwal, "An epidemiological study of vulvovaginal candidiasis in women of childbearing age," Indian Journal of Medical Microbiology, vol. 25, no. 2, pp. 175-176, 2007.

[24] V. F. Go, V. M. Quan, D. D. Celentano, L. H. Moulton, and J. M. Zenilman, "Prevalence and risk factors for reproductive tract infections among women in rural Vietnam," Southeast Asian Journal of Tropical Medicine and Public Health, vol. 37, no. 1, pp. 185-189, 2006.

[25] J. M. Achkar and B. C. Fries, "Candida infections of the genitourinary tract," Clinical Microbiology Reviews, vol. 23, no. 2, pp. 253-273, 2010.

[26] S. Mohanty, I. Xess, F. Hasan, A. Kapil, S. Mittal, and J. E. Tolosa, "Prevalence \& susceptibility to fluconazole of Candida species causing vulvovaginitis," Indian Journal of Medical Research, vol. 126, no. 3, pp. 216-219, 2007.

[27] M. Cetin, S. Ocak, A. Gungoren, and A. U. Hakverdi, "Distribution of Candida species in women with vulvovaginal symptoms and their association with different ages and contraceptive methods," Scandinavian Journal of Infectious Diseases, vol. 39, no. 6-7, pp. 584-588, 2007.

[28] R. Manandhar, J. Sharma, B. Pokharel, B. Shrestha, and N. Pradhan, "Bacterial vaginosis in Tribhuvan University Teaching Hospital," Journal of Institute of Medicine, vol. 27, no. 2, pp. 2-5, 2007.

[29] P. S. Rao, S. Devi, A. Shriyan, M. Rajaram, and K. Jagdishchandra, "Diagnosis of bacterial vaginosis in a rural setup: comparison of clinical algorithm, smear scoring and culture by semiquantitative technique," Indian Journal of Medical Microbiology, vol. 22, no. 1, pp. 47-50, 2004.

[30] P. Bhalla, R. Chawla, S. Garg et al., "Prevalence of a bacterial vaginosis among women in Delhi, India," Indian Journal of Medical Research, vol. 125, no. 2, pp. 167-172, 2007.

[31] C. M. Muvunyi and T. C. Hernandez, "Prevalence of bacterial vaginosis in women with vaginal symptoms in South Province, Rwanda," African Journal of Clinical and Experimental Microbiology, vol. 10, no. 3, pp. 156-163, 2009.

[32] A. Kumar Aggarwal, R. Kumar, V. Gupta, and M. Sharma, "Community based study of reproductive tract infections among ever married women of reproductive age in a rural area of Haryana, India," Journal of Communicable Diseases, vol. 31, no. 4, pp. 223-228, 1999.
[33] Z. Mengistie, Y. Woldeamanuel, D. Asrat, and A. Adera, "Prevalence of bacterial vaginosis among pregnant women attending antenatal care in Tikur Anbessa University Hospital, Addis Ababa, Ethiopia," BMC Research Notes, vol. 7, article 822, 2014.

[34] Z. A. Abdelaziz, M. E. Ibrahim, N. E. Bilal, and M. E. Hamid, "Vaginal infections among pregnant women at Omdurman Maternity Hospital in Khartoum, Sudan," Journal of Infection in Developing Countries, vol. 8, no. 4, pp. 490-497, 2014.

[35] P. R. Mason, Heather Super, and P. J. Fripp, "Comparison of four techniques for the routine diagnosis of Trichomonas vaginalis infection," Journal of Clinical Pathology, vol. 29, no. 2, pp. 154$157,1976$.

[36] P. Madhivanan, M. T. Bartman, L. Pasutti et al., "Prevalence of Trichomonas vaginalis infection among young reproductive age women in India: Implications for treatment and prevention," Sexual Health, vol. 6, no. 4, pp. 339-344, 2009.

[37] P. A. deLemos, M. T. Gracia-Zapata, N. M. Guimaraes, and R. G. Moris, "Comparison of methods for identification of Trichomonas vaginalis in HIV positive and negative women," International Journal of Tropical Medicine, vol. 4, no. 2, pp. 7681, 2009.

[38] S. R. Fule, R. P. Fule, and N. S. Tankhiwale, "Clinical and laboratory evidence of Trichomonas vaginalis infection among women of reproductive age in rural area," Indian Journal of Medical Microbiology, vol. 30, no. 3, pp. 314-316, 2012. 


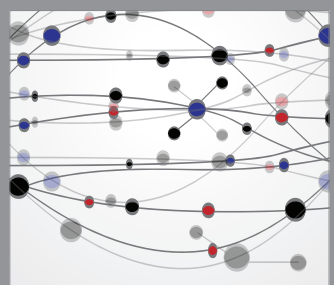

The Scientific World Journal
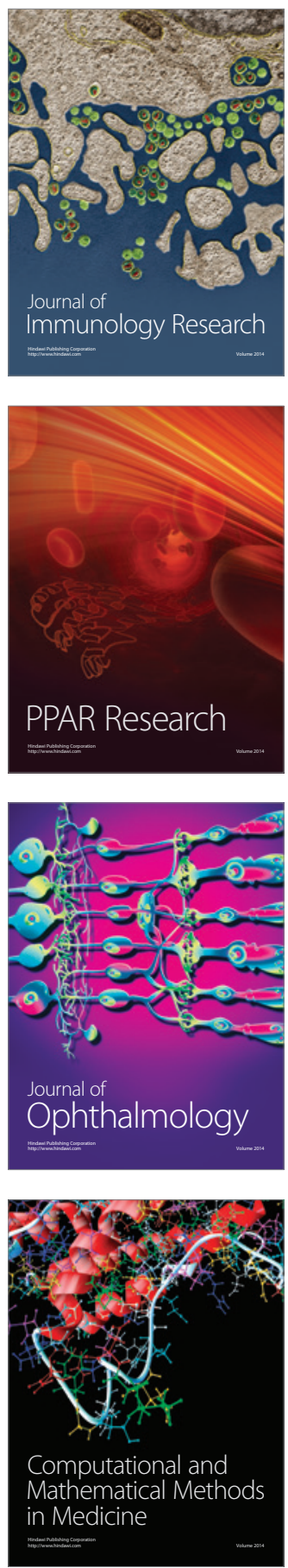

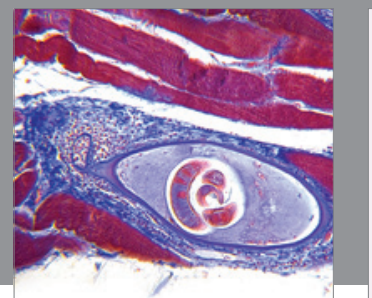

Gastroenterology

Research and Practice
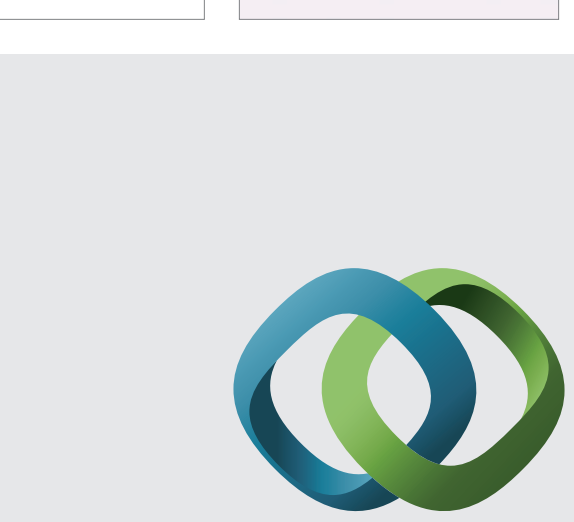

\section{Hindawi}

Submit your manuscripts at

http://www.hindawi.com
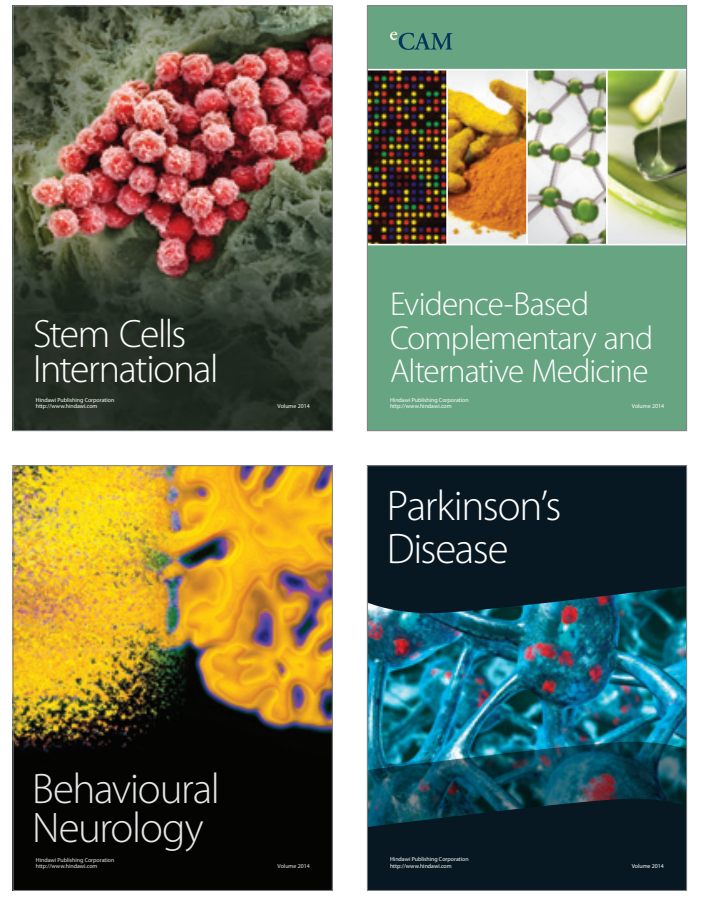
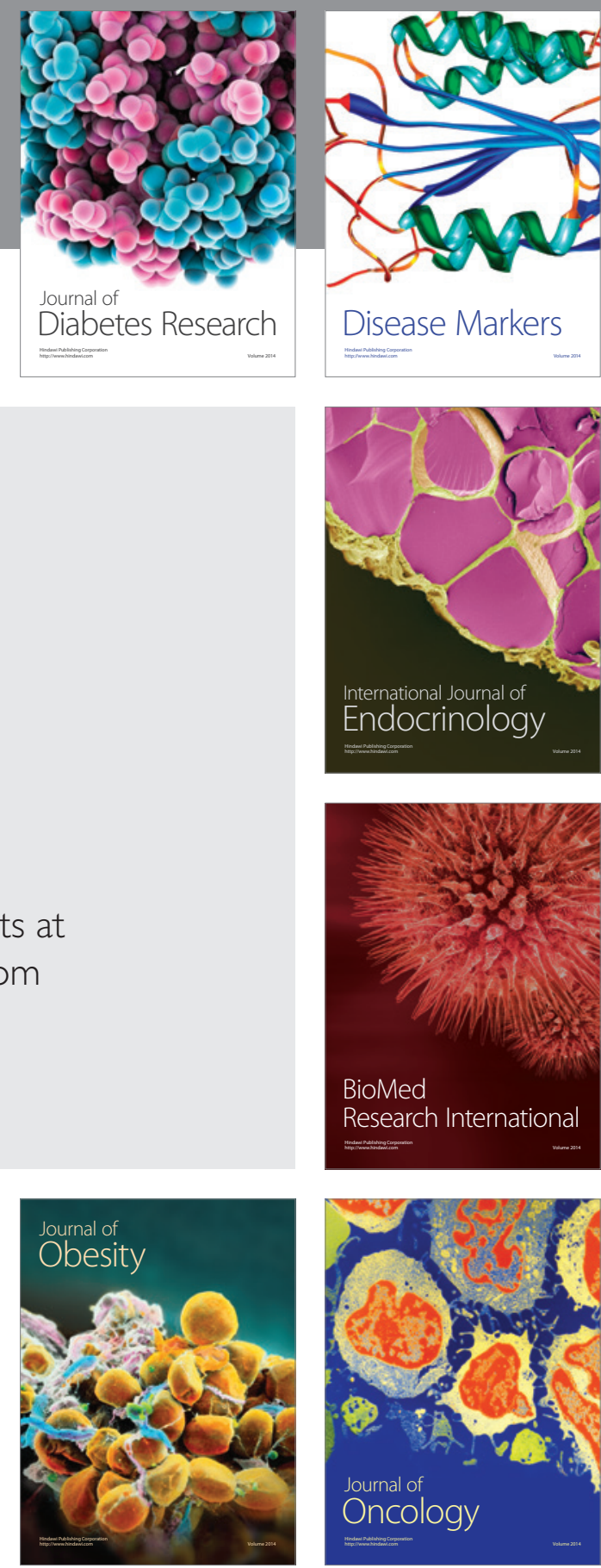

Disease Markers
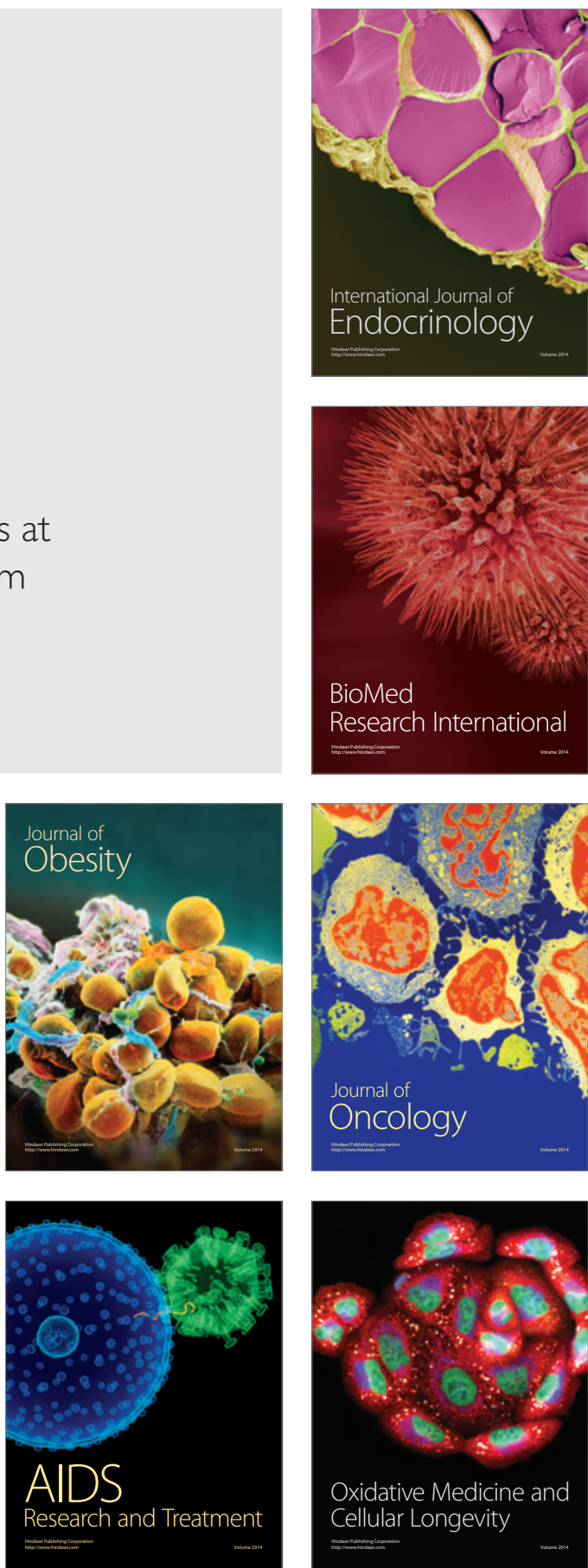